\title{
Effect of macrostructure on the thermoelectric properties of biomorphous $\mathrm{SiC} / \mathrm{Si}$ ceramics
}

\author{
V.S. Kiselov $^{{ }^{*}}$, V.I. Poludin ${ }^{1}$, M.P. Kiselyuk ${ }^{1}$, T.A. Kryskov ${ }^{2}$ and A.E. Belyaev ${ }^{1}$ \\ ${ }^{I}$ V. Lashkaryov' Institute of Semiconductor Physics, NAS of Ukraine, 41, prospect Nauky, 03028 Kyiv, Ukraine \\ ${ }^{2}$ Kamenets-Podolskiy National University, 61, Ogiyenko str., 32300 Kamenets-Podolskiy, Ukraine \\ *Corresponding author - e-mail:vit_kiselov@ukr.net
}

\begin{abstract}
In this work, effect of porous macrostructure on the thermoelectric properties of biomorphous $\mathrm{SiC} / \mathrm{Si}$ ceramics prepared by the liquid silicon infiltration process has been investigated. Temperature dependences of the conductivity and thermal e.m.f. have been measured within the range $20-700{ }^{\circ} \mathrm{C}$. It has been shown that electrical resistivity of the samples decreases drastically as temperature increases over the entire temperature range, indicating semiconductor behavior. All the samples demonstrate a negative thermal e.m.f. confirming the electronic mechanism of charge transfer. It is ascertained that anisotropy of porous macrostructure of the ceramics influences considerably on their electric and thermoelectric properties. The figure of merit maximum value of $1.2 \times 10^{-5} \mathrm{~K}^{-1}$ at $700{ }^{\circ} \mathrm{C}$ was obtained.
\end{abstract}

Keywords: biomorphous $\mathrm{SiC}$ ceramics, thermoelectric properties, electrical conductivity, macrostructure.

Manuscript received 02.12.08; accepted for publication 18.12.09; published online 02.03.09.

\section{Introduction}

The thermoelectric effect that offers a technology providing direct conversion of thermal energy to electricity is of great scientific and technological interest. Thermoelectric converters ensure an ecological process for power generation without pollution of the environment. To obtain materials possessing improved thermoelectric characteristics, intensive investigations of heavily doped semiconductors, advanced alloys and low dimensional structures are performed. Recently, thermoelectric materials, like BiTe [1, 2], PbTe [3], SiGe [4], etc., having satisfactory parameters have been manufactured.

It is known that porous ceramics based on silicon carbide is characterized by a set of attractive properties, namely: mechanical strength, corrosion and oxidation resistance, low specific weight, large surface area $\left(\approx 1000 \mathrm{~m}^{2} \mathrm{~g}^{-1}\right)$, as well as resistance to thermal shocks should be noted. Recently, the reports concerning promising thermoelectric characteristics of $\mathrm{SiC}$ based porous ceramics have been appeared [5-9]. One of the methods for obtaining porous $\mathrm{SiC} / \mathrm{Si}$ ceramics is the steeping of carbon matrix by liquid silicon. Variety kinds of wood subjected to pyrolysis were used as carbon based matrix. This material is called as biomorphous ceramics. It should be noted that carbon based matrix made from wood corresponds to the material with open porosity that provides the possibility for their steeping by silicon. Moreover, the wood has strong anisotropy of properties due to complex structure. The fact can affect on electric and thermoelectric properties of porous biomorphous $\mathrm{SiC} / \mathrm{Si}$ ceramics. In this work, the influence of porous macrostructure on the thermoelectric properties of biomorphous $\mathrm{SiC}$ ceramics is investigated.

\section{Porous $\mathrm{SiC}$ ceramics growth technology}

The steeping of carbon matrix by liquid silicon, the socalled liquid silicon infiltration process (LSI-process), was used to obtain porous $\mathrm{SiC} / \mathrm{Si}$ ceramics [10-13]. The LSI-process is based on the impregnation of porous carbon templates by molten silicon and its reaction to silicon carbide. The Persian Walnut (Juglans regia), beech (Fagus sylvatica), alder (Alnus glutinosa), European Hornbeam (Carpinus betulus), and pear tree (Pyrus domestica) available in Ukraine with average dimensions of $30 \mathrm{~mm}$ in diameter and height of $45 \mathrm{~mm}$ were used as the biological template in this study. At the initial stage, wood samples were pyrolyzed at $900{ }^{\circ} \mathrm{C}$ in an argon atmosphere. After pyrolysis, the carbon templates were reacted with liquid silicon produced by melting $\mathrm{Si}$ powder at $1600-1900{ }^{\circ} \mathrm{C}$ in a graphite 
crucible in inert (Ar) atmosphere. The weight ratio of $\mathrm{Si} / \mathrm{C}$ was equal to 2.5-3.5. Liquid silicon penetrated through porous medium into matrix. As a result, fusion reaction has been realized

$\mathrm{C}(\mathrm{sol})+\mathrm{Si}(\mathrm{liq}) \rightarrow \mathrm{SiC}$.

To control the silicon infiltration process as well as the fusion reaction, some of technology stages were carried out in vacuum or in helium atmosphere. In the case of need, residual carbon was removed by firing in oxygen atmosphere at $800-900{ }^{\circ} \mathrm{C}$.

\section{Results and discussion}

The standard technique of optical and scanning electron microscopy was used to study the structure of ceramics. The stationary method was used to measure the thermoe.m.f. The samples were prepared in the form of parallelepiped or cylinder. The electric conductivity and Seebeck coefficient were measured in air under different orientations of the samples with respect to the wood growth axis. The sample temperature was controlled by an alumel-chromel thermocouple. The electric contacts were fabricated by deposition of $\mathrm{Ti}+\mathrm{Ni}$ or by baking of powder mixture of $\mathrm{W}+\mathrm{Ni}$.

The view of ceramics' surface in cross-section perpendicular to the wood growth axis is shown in Fig. 1. The peculiarities of the wood structure allow

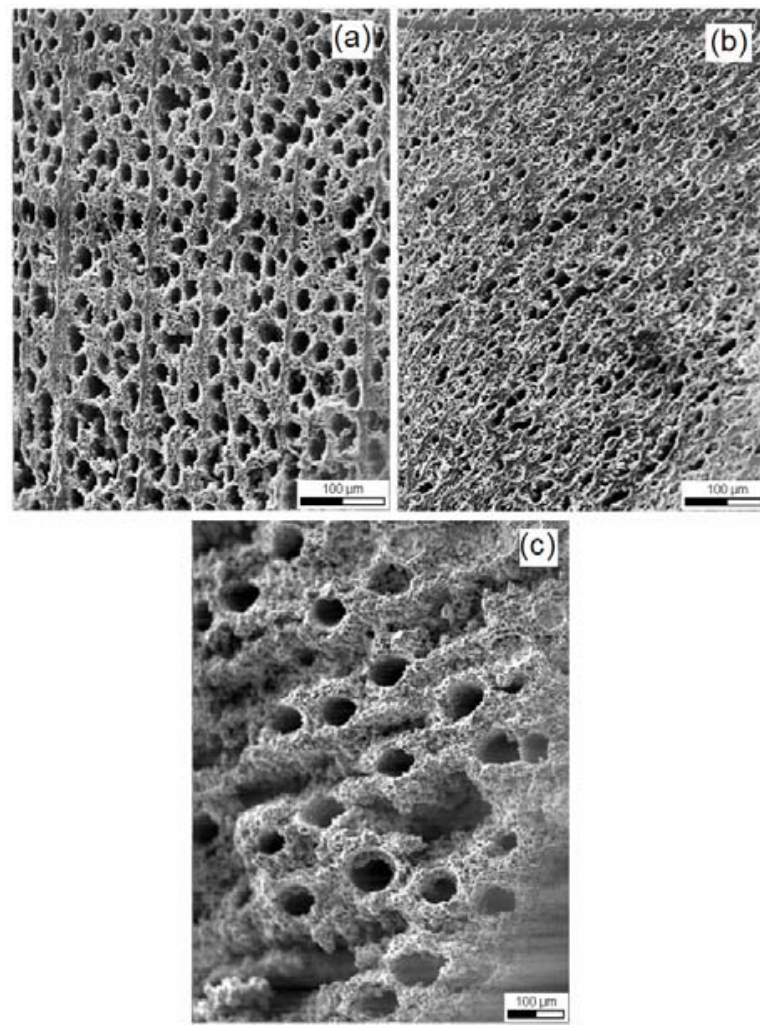

Fig. 1. SEM views of surface of the biomorphous-SiC ceramics fabricated from different kinds of wood: $(a)-$ beech, $(b)$ - pear tree and $(c)$ - Persian Walnut. fabrication of porous ceramics with different orientations corresponding to the growth direction and annual layers. Two sets of samples have been studied. As it is seen from Fig. 2, in the samples of type-I the electric current direction coincides with the wood growth axis, while in the samples of type-II the current flows perpendicular to the growth direction and annual layers. The samples of type-II are characterized by existence of periodic layers with repetition equal to the size of annual layers. The number of periodic layers $\theta$ depends on the kind of wood and geometry of a sample.

The resistivity of $\mathrm{SiC}$ ceramics decreases considerably as temperature increases over the entire temperature range measured, which is typical for semiconductors. Besides, it is seen in Fig. 3 that biomorphous $\mathrm{SiC} / \mathrm{Si}$ ceramics demonstrates essential anisotropy of electric properties. The ratio of specific resistivity for the samples of both types $\rho_{\text {(II-type) }} / \rho_{\text {(I-type) }}$ depends on $\theta$ value and can approach the amplitude up to 10 .

Fig. 4 illustrates the influence of macrostructure on the thermo-e.m.f. for biomorphous $\mathrm{SiC} / \mathrm{Si}$ ceramics fabricated from different kinds of wood. The Seebeck coefficient, $\alpha$, in all the samples has a negative value that corresponds to the electronic mechanism of charge transfer. The absolute value of $\alpha$ increases with elevating temperature and demonstrates a certain correlation with the structure of $\mathrm{SiC}$ ceramics. For example, as can be seen from Fig. 5, increase of the number of layers $\theta$ brings the increase of the Seebeck coefficient. The highest magnitude of $\alpha$ observed in some samples approached the value of $-200 \mu \mathrm{V} \cdot \mathrm{K}^{-1}$.

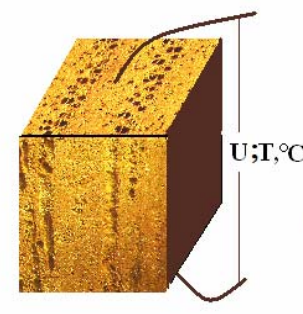

(I)

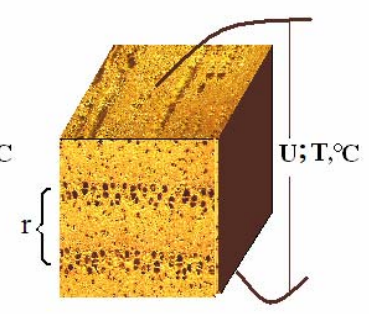

(II)
Fig. 2. Schematic view of the bio-SiC thermoelectric converters: (I) - electric current direction coincides with the wood growth axis; (II) - the current flows perpendicular to growth direction and annual layers; $r$ - thickness of the wood annual layer.

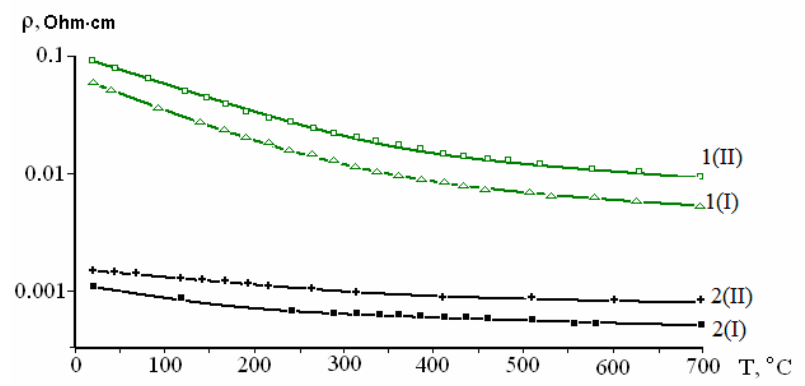

Fig. 3. Temperature dependence of specific resistivity for ceramics fabricated from beech (1) and pear tree (2).

\section{(C) 2009, V. Lashkaryov Institute of Semiconductor Physics, National Academy of Sciences of Ukraine}




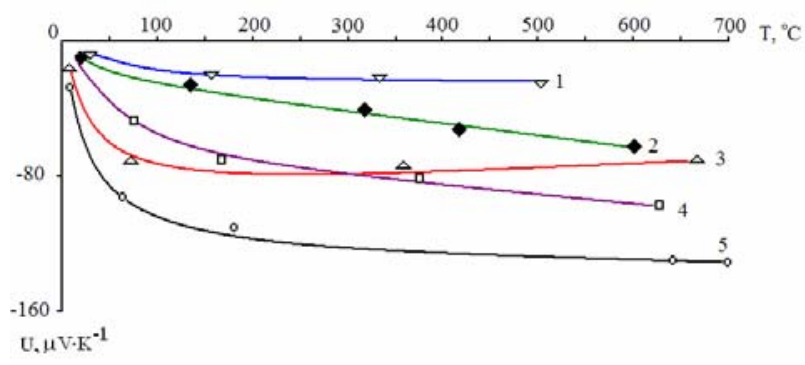

Fig. 4. Temperature dependence of the Seebeck coefficient for samples of type-I fabricated from alder (1), European Hornbeam (2), Persian Walnut (3), beech (4), and pear tree (5).

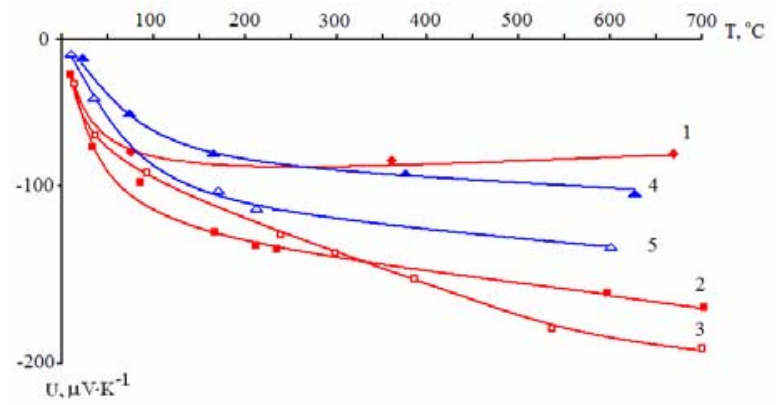

Fig. 5. Temperature dependence of the Seebeck coefficient for samples of type-I and type-II fabricated from Persian Walnut $(1-$ type-I, 2 - type-II, $\theta=4,3-$ type-II, $\theta=10)$ and beech (4 - type-I, 5 - type-II, $\theta=5$ ).

The figure of merit of the sample was calculated using the following equation:

$\mathrm{Z}=\left(\alpha^{2} / \rho \lambda\right)$,

where $Z$ is figure of merit $\left(\mathrm{K}^{-1}\right), \alpha$ is the Seebeck coefficient $(\mathrm{V} / \mathrm{K}), \rho$ is the specific resistivity $(\mathrm{Ohm} \cdot \mathrm{m}), \lambda$ is the thermal conductivity $\left(\mathrm{W} \cdot \mathrm{m}^{-1} \cdot \mathrm{K}^{-1}\right)$. Obviously, the high quality thermoelectric materials should possess a high value of the Seebeck coefficient, low thermal conductivity that must support the temperature gradient and good electric conductivity.

Thermal conductivity is an important factor that will affect the figure of merit. In this connection, porous material has the advantage over the bulk one. Indeed, it is well known that the thermal conductivity of bulk $\mathrm{SiC}$ exceeds that of porous $\mathrm{SiC}$ by several times.

The data concerning the thermal conductivity of porous $\mathrm{SiC}$ ceramics fabricated by different methods are presented in Table.

Table. Thermal conductivity of $\mathrm{SiC}$ ceramics.

\begin{tabular}{|c|c|c|}
\hline $\begin{array}{c}\text { Growth technology and } \\
\text { composition }\end{array}$ & $\begin{array}{c}\lambda, \mathrm{W} \cdot \mathrm{m}^{-1} \cdot \mathrm{K}^{-1}, \\
T=600{ }^{\circ} \mathrm{C}\end{array}$ & Reference \\
\hline $\begin{array}{c}\text { Porous } \mathrm{SiC} / \mathrm{C} \text { composite } \\
\text { made from a mixed } \\
\text { powder of wood charcoal } \\
\text { and } \mathrm{SiO}_{2}\end{array}$ & $4-25$ & {$[7]$} \\
\hline $\begin{array}{c}\text { Synthesis from } \mathrm{SiC} \text { and } \mathrm{Si} \\
\text { powders }\end{array}$ & 20 & {$[8]$} \\
\hline Composite $\mathrm{SiC}+(15 \% \mathrm{Si})$ & 22.7 & {$[9]$} \\
\hline
\end{tabular}

It is seen that the thermal conductivity of porous $\mathrm{SiC}$ ceramics fabricated by different methods varies from 4 to $25 \mathrm{~W} \cdot \mathrm{m}^{-1} \cdot \mathrm{K}^{-1}$ at $T=600{ }^{\circ} \mathrm{C}$. These values were used to estimate the figure of merit for biomorphous $\mathrm{SiC}$ ceramics. The samples of type-I fabricated from pear tree wood showed the best results. Due to the low specific resistivity $\left(\rho<4 \times 10^{-4} \mathrm{Ohm} \cdot \mathrm{m}\right)$ and high value of the Seebeck coefficient $(\alpha>140 \mathrm{~V} / \mathrm{K})$, the figure of merit for these samples approaches the value of $1.2 \times 10^{-5} \mathrm{~K}^{-1}$ at $700{ }^{\circ} \mathrm{C}$, which is in good agreement with data obtained in Ref. [7].

\section{Conclusions}

Study of structure, electric and thermoelectric characteristics of biomorphous $\mathrm{SiC} / \mathrm{Si}$ ceramics grown using the liquid silicon infiltration process has been carried out. It is observed that the electrical resistivity of $\mathrm{SiC}$ ceramics decreases considerably as temperature increases over the entire temperature range measured, which is indicative of semiconductor behavior. All the samples demonstrate a negative thermal e.m.f. confirming the electronic mechanism of charge transfer. The absolute value of $\alpha$ increases with elevating temperature and demonstrates a certain correlation with the structure of $\mathrm{SiC}$ ceramics. It has been shown that efficiency of thermoelectric conversion in biomorphous $\mathrm{SiC} / \mathrm{Si}$ ceramics increases with temperature rise. The samples of $\mathrm{SiC}$ ceramics of type-I demonstrate the highest values of the figure of merit. According to our estimation, the figure of merit for these samples approaches the value of $1.2 \times 10^{-5} \mathrm{~K}^{-1}$ at $700^{\circ} \mathrm{C}$. We suppose that optimization of $3 \mathrm{D}$ macroporous structure of the biomorphous ceramics as well as enhancement of electric conductivity by doping should improve thermoelectric properties of $\mathrm{SiC}$ materials.

\section{References}

1. Dong-Hwan Kim, Tadaoki Mitani, Thermoelectric properties of fine-grained $\mathrm{Bi}_{2} \mathrm{Te}_{3}$ alloys // J. Alloys Compounds, 399 (1-2), p. 14-19 (2005).

2. D.Y. Chung, T. Hogan, P. Brazis, M. Roccilane, C. Kannewurf, M. Bastea, C.U. Mercouri, G. Kanatzidis, $\mathrm{CsBi}_{4} \mathrm{Te}_{6}$ : a high-performance thermoelectric material for low-temperature applications // Science 287, p. 1024 (2000).

3. Yasutoshi Noda, Masaki Orihashi, Isao A. Nishida, Thermoelectric properties of p-type lead telluride doped with silver or potassium // Mater. Trans. 39, p. 602 (1998).

4. C.M. Bhandari, D.M. Rowe, Silicon-germanium alloys as high-temperature thermoelectric materials // Contemp. Phys. 21, p. 219 (1980).

5. K. Koumoto, M. Shimohigoshi, S. Takeda, and H. Yanagida, Thermoelectric energy conversion by porous $\mathrm{SiC}$ ceramics // J. Mater. Sci. Lett. 6, p. $1453-1455$ (1987). 
6. M. Fujisawa, T. Hata, P. Bronsveld, V. Castro, F. Tanaka, H. Kikuchi, Y. Imamura, Thermoelectric properties of $\mathrm{SiC} / \mathrm{C}$ composites from wood charcoal by pulse current sintering // J. Europ. Ceram. Soc. 25, p. 2735-2738 (2005).

7. M. Fujisawa, T. Hata, H. Kitagawa, P. Bronsveld, Y. Suzuki, K. Hasezaki, Y. Noda, Y. Imamura, Thermoelectric properties of porous $\mathrm{SiC} / \mathrm{C}$ composites // Renewable Energy 33, p. 309-313 (2008).

8. Wei Wei, Jia-wei Li, Hong-tao Zhang, Xiao-ming Cao, Chong Tian, Jin-song Zhanga, Macrostructural influence on the thermoelectric properties of SiC ceramics // Scripta Materialia 57, p. 10811084 (2007).

9. Wei Wei, Xiao-ming Cao, Chong Tian, Jin-song Zhanga, The influence of $\mathrm{Si}$ distribution and content on the thermoelectric properties of $\mathrm{SiC}$ foam ceramics // Microporous and Mesoporous Materials 112 (1-3), p. 521-525 (2008).
10. R. Kochendorfer, W. Krenkel, High-temperature ceramic-matrix composites I: Design durability and performance. In: A.G. Evans, R. Naslain (Eds.) // Ceramic Transactions 57, American Ceramic Society, p. 13-22 (1995).

11. F.M. Varela-Feria, J. Martinez-Fernandez, A.R. de Arellano-Lopez, M. Singh, Low density biomorphic silicon carbide: microstructure and mechanical properties // J. Europ. Ceram. Soc. 22, p. 2719-2725 (2002).

12. P. Greil, Biomorphous ceramics from Lignocellulosics // J. Europ. Ceram. Soc. 21, p. 105-118 (2001).

13. V.S. Kiselov, E.N. Kalabukhova, A.A. Sitnikov, P.M. Lytvyn, V.I. Poludin, V.O. Yukhymchuk, and A.E. Belyaev, Effect of Si infiltration method on the biomorphous $\mathrm{SiC}$ microstructure properties. NANSIS-2007, Ukraine, Kiev, 2007, p. 571. 